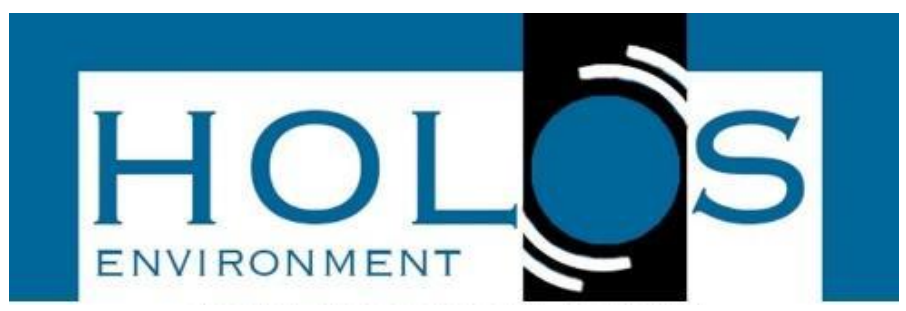

\title{
IMOBILIZAÇÃO ENZIMÁTICA EM SUPORTES ORGÂNICOS E INORGÂNICOS: VANTAGENS E DESVANTAGENS
}

\section{ENZYME IMMOBILIZATION IN ORGANIC AND INORGANIC SUPPORTS: ADVANTAGES AND DISADVANTAGES}

\author{
Daniel Delgado Queissada ${ }^{1}$; Jesiel Alves da Silva ${ }^{1}$
}

Artigo recebido em: 24/02/2020 e aceito para publicação em: 16/03/2020.

DOI: http://dx.doi.org/10.14295/holos.v20i2.12378

\begin{abstract}
Resumo: $O$ interesse na imobilização enzimática é alcançar um biocatalisador com atividade e estabilidade que não sejam afetadas durante o processo e que proporcione o máximo de reutilização da enzima frente aos parâmetros que podem inativar a mesma (temperatura, solventes orgânicos, etc.), cooperando com o meio ambiente e, ao mesmo tempo, otimizando a produção industrial. Este trabalho tem como objetivo principal descrever a imobilização enzimática em suportes orgânicos e inorgânicos, destacando as principais vantagens e desvantagens de cada sistema.Conclui-se que o uso da imobilização enzimática é menos prejudicial para o meio ambiente, contudo a escolha do melhor tipo de suporte, dependendo do objetivo da produção, é fundamental para o sucesso, tanto ambiental como industrial, do processo. Assim, deve-se levar em consideração as principais vantagens e desvantagens de cada técnica utilizada.
\end{abstract}

Palavras-chave: Imobilização enzimática. Suportes orgânicos. Suportes inorgânicos.

\begin{abstract}
The interest in enzyme immobilization is to achieve a biocatalyst with activity and stability that are not affected during the process and providing the maximum reuse of the enzyme against the parameters that can inactivate the same (temperature, organic solvents, etc.), cooperating with the environment and, at the same time, optimizing industrial production. This work has as its main objective to describe enzyme immobilization in organic and inorganic supports, highlighting the main advantages and disadvantages of each system. It is concluded that the use of the enzyme immobilization is less harmful to the environment, however the choice of the best type of support, depending on the purpose of the production, it is essential for success, both as industrial, environmental process. Thus, one must take into consideration the main advantages and disadvantages of each technique
\end{abstract}

Keywords: Enzyme immobilization. Organic supports. Inorganic supports.

\section{INTRODUÇÃO}

O uso de enzimas pelos homens não é recente. Nos tempos dos povos egípcios já era produzido a cerveja e vinho com a utilização da técnica de fermentação enzimática, mesmo sem a compreensão dos mecanismos que regiam o processo. A técnica que é

\footnotetext{
1 Universidade de São Paulo (USP), São Paulo, SP. E-mail: (queissada@gmail.com, jesielpa2016@gmail.com)
} 
usada mais recentemente e que foi a primeira no ramo da utilização de enzimas na indústria é a biocatálise, descrita pela primeira vez, quando se estudava a digestão de estudos da digestão de carnes por secreções de estômago (HOMAEl et al., 2013).

Estas substâncias podem acelerar uma reação química sem que ela seja alterada, essas são chamadas de catalisadores. As enzimas servem de catalisadores biológicos nas células vivas e são específicas para cada composto, esse chamado de substrato. A enzima orienta o substrato para uma posição que aumente a probabilidade de uma reação, enquanto o complexo enzima-substrato formado pela ligação temporária da enzima com os reagentes permite que as colisões sejam mais eficientes, diminuindo a energia de ativação da reação (ZHANG et al., 2018).

Segundo Donald, Judith e Charlotte (2014), as enzimas diferem dos demais catalisadores químicos por possuir uma velocidade de reação rápida, sendo $10^{6}$ a $10^{12}$ maiores que as reações correspondentes não catalisadas; condições reacionais mais leves; maior especificidade da reação e capacidade de regulação. A classificação enzimática é dada de acordo com a natureza de reação química que catalisam: Oxidorredutores (reação de oxidação-redução); Transferase (transferências de grupos funcionais); Hidrolase (reação de hidrólise); Liases (eliminação de grupos para formar ligações duplas); Isomerase (isomerização) e Ligases (formação de ligação acoplada à hidrólise).

Atualmente as enzimas possuem amplos benefícios, sobretudo no meio industrial. Assim, diversas enzimas são comercializadas, como por exemplo as amilases, proteases, lipases, celulases e a tendência é que a cada passo no desenvolvimento das pesquisas a procura por esses produtos cresçam. Existe uma estimativa de que o mercado de enzimas industriais movimente uma receita de até U\$6.3 bilhões em 2022 (KIRAN et al., 2018).

O sucesso de uma enzima na catalização está diretamente relacionado com o desempenho do suporte. Logo na escolha de um determinado suporte é observado suas propriedades físicas e químicas e possibilidade de regeneração do material, como também a área superficial,insolubilidade, permeabilidade, morfologia e natureza hidrofílica ou hidrofóbica, resistência ao ataque microbiano, resistência mecânica, custo, entre outros (FLORES, 2018).Assim, o presente trabalho objetivou descrever as vantagens e desvantagens da imobilização enzimática em suportes orgânicos e inorgânicos.

\section{MATERIAL E MÉTODOS}

O trabalho realizado foi baseado em revisão bibliográfica principalmente de artigos 
científicos, além de sites governamentais. A pesquisa deu prioridade a publicações mais recentes.

Dentre as bases de dados pesquisadas encontram-se os Periódicos Capes, Scielo, Elsevier, etc. Para os critérios de inclusão e exclusão levou-se em consideração que o material estivesse principalmente dentro do período dos últimos cinco anos, salvo aquelas oriundas e consagradas em trabalhos da área específica, além de terem origem em revistas científicas e/ou instituições públicas de qualidade, tanto em português como em inglês.

Os materiais encontrados foram selecionados de acordo com sua pertinência ao tema abordado, ou seja, os processos de imobilização enzimática, focando nas vantagens e desvantagens dos suportes orgânicos e inorgânicos.

\section{DISCUSSÃo}

\subsection{Uso de enzimas imobilizadas}

As principais enzimas de aplicação industrial são proteases, amilases, lipases, celulases, xilanases e fitases. Tendo como exemplo a lipase, que tem sido bastante utilizada na indústria por ter uma capacidade de hidrolisar triglicerídeos na interface óleoágua que, em condições fisiológicas,catalisa a hidrólise das ligações de éster nas moléculas de triglicerídeos liberando assim gratuitamente ácidos graxos, glicerol, diglicerídeos e monoglicerídeos. Essa enzima também catalisa reações como esterificação, transesterificação, aminólise e lactonização. Contudo, as enzimas apresentam desvantagens quanto a estabilidade operacional e de armazenamento, pois são moléculas complexas e altamente sensíveis. Porém, o avanço do processo de imobilização em vários tipos de suportes, por diferentes protocolos, permitiu melhorar sensivelmente a estabilidade térmica das enzimas (MÖRSCHBÄCHER, VOLPATO, SOUZA, 2016; GENNARI et al., 2018).

Para além dos suportes que são utilizados no uso de enzimas imobilizadas, como os materiais inorgânicos, polímeros sintéticos e naturais descritos a exemplo por Datta et al. (2013), pesquisas recentes vem chamando a atenção da industria pelo desenvolvimento de novas maneiras de imobilização que mesmo sem ter o mesmo aproveitamento das demais metodologias, em algumas situações tem apresentado bons resultados, que é o uso de liquidos iônicos que no trabalho de Xiang et al. (2018) em que foi imobilizado a lipases sobre nanomateriais híbridos de sílica quitosanamesoporosa por líquidos iônicos e foi obtido nos 
resultados que os nanomateriais híbridos podem formar estruturas tridimensionais com estruturas mesoporosa homogêneas e lipase imobilizada, concluindo que seu desempenho enzimático foi ótimo, evidenciado ainda pelo trabalho de Wang; Caruso (2005) intitulado de esferas mesoporosas de sílica como suporte para imobilização e encapsulação de enzimas.

Contudo, LI et al. (2018) destacam que ainda existe uma enorme limitação no uso de produtos de interesse industrial devido à baixa versatilidade de alguns catalisadores, queexigem altas temperaturas para atingir a velocidade de reação eficiente. Sendo que o produto obtido muitas vezes é contaminado pelo catalisador, necessitando de um processo de purificação no final da sua produção.

\subsection{Imobilização enzimática}

A imobilização de enzima é uma importante ferramenta capaz de processar a aplicação de biocatalisadores, permitindo a reutilização e redução de sua inativaçãopor meio de temperatura e solventes orgânicos, melhorando a estabilidade operacional da enzima. Além de aliviar a separação de enzimas do ambiente de reação e eliminar o risco contaminação do biocatalisador do produto final (MEI et al., 2018; ZUCCA;SANJUST, 2014), em outras palavras, é uma chave que cria condições favoráveis no desempenho de atividade de determinada enzima nos processos industriais (SHELDON, 2007).

Assim a imobilização torna-se um método vantajoso por melhorar estabilidade de biocatalisadores e fornecer para a sua utilização frequente a fácil separação do meio de reação (MINTEER, 2011; TRAN; BALKUS, 2011; ALTINKAYNAK; TAVLASOGLU; OCSOY, 2016), logo, a imobilização consiste no confinamento da enzima em um suporte sólido para posterior reutilização do biocatalisador, tornando o processo menos oneroso, além de aumentar o potencial de uma enzima como catalisador com interesse industrial, podendo ser utilizada para estabilizar enzimas e reduzir ou ter efeito na estabilidade, a depender de seu suporte (OLIVEIRA, 2014; FLORES, 2018). Tabela 1 mostra as vantagens e desvantagens da imobilização enzimática. 
Tabela 1 - Vantagens e desvantagens da imobilização enzimática.

\section{VANTAGENS}

Maior estabilidade

Fácil separação enzima-produto Reator enzimático Reutilização do derivado

\section{DESVANTAGENS}

Alteração da conformidade

Grande heterogeneidade

Menor atividade enzimática

Biocatalizador mais caro que enzima nativa

Fonte: Cabrera (2013)

\subsection{Processos de imobilização enzimática}

Existe métodos para a imobilização (SASSOLAS; BLUM; LECA-BOUVIER, 2012), e estes são divididos em três categorias: adsorção num suporte, ligação covalente em um suporte, encapsulamento eenzimas reticuladas, interação de afinidade. A imobilização de enzimas em suportes sólidos permite a sua reutilização (LI et al., 2016) e fácil manuseio, pois melhora a estabilidade do catalisador, que são importantes para o desenvolvimento de processos biotecnológicos econômicos. O processo de adsorção física é dado como simples. A imobilização de enzimas em suportes sólidos é prática, e por isso torna-se econômico e vantajoso pela facilidade no manuseio e por serem recuperadas em qualquer tempo de reação sem considerável perda da atividade catalítica (SHELDON; VAN PELT, 2013; VASCONCELLOS, 2015).

Figura 2 - Esquema dos métodos de imobilização de enzimas
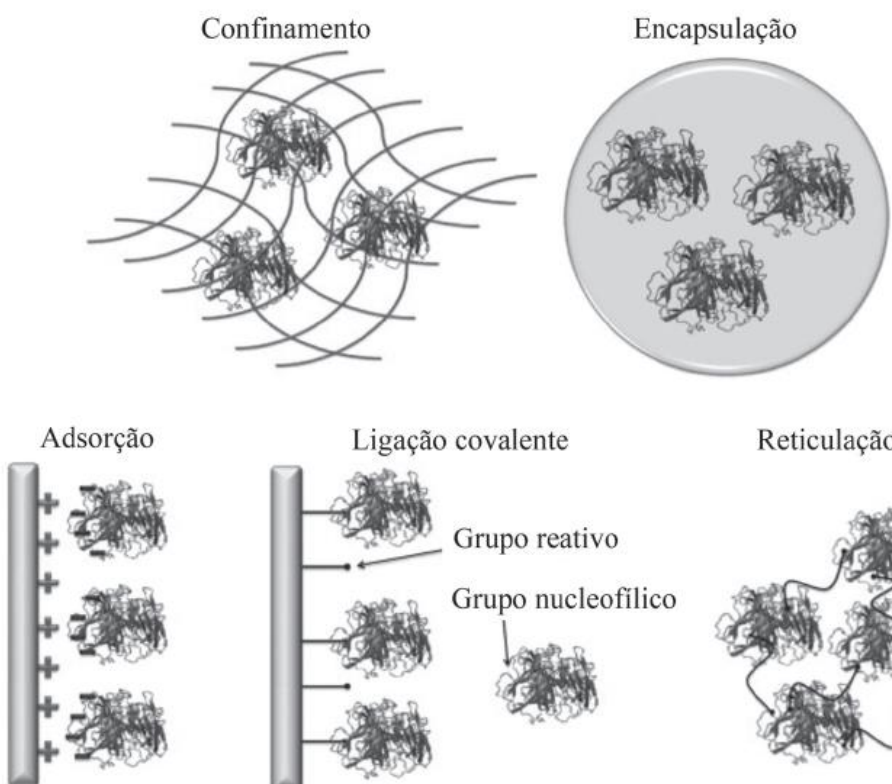

Ligação covalente

Reticulação

Fonte: Fernández-Fernández et al. (2013)

O bom desempenho de uma enzima catalisadora está diretamente relacionado com 
odesempenho do suporte (ZUCCA; SANJUST., 2014; FLORES, 2018; PEREIRA, 2015). $\mathrm{Na}$ escolha de um determinado suporte devem ser observadas suas propriedades físicas e químicas e possibilidade de regeneração do material, como também a área superficial, resistência ao ataque microbiano, (HARTMANN;KOSTROV, 2013), insolubilidade, permeabilidade, morfologia e natureza hidrofílica ou hidrofóbica(RODRIGUES et al., 2013), resistência mecânica (WEETALL, 1976),entre outros.

Segundo Nadar; Rathod (2018), a imobilização de enzimas por ligações covalentes acontece pela formação de ligações entre os resíduos de aminoácidos que constituem a enzima e que não são essenciais para sua atividade catalítica e os grupos reativos atuais na superfície do suporte.A vantagem é que esse processo possui maior estabilidade enzimática em relação aos efeitos do ambiente reacional, como variação de $\mathrm{pH}$, temperatura, solventes e ação de inibidores, além de evitar a dessorção da enzima do suporte. Contudo,também possui desvantagens, devido à interação mais forte entre a enzima e o suporte, esse método pode afetar a estruturatridimensional da enzima, modificando seu sítio ativo, e diminuindo efetivamente a sua atividade catalíticaZHOU; HARTMANN, 2012).

Segundo Lima (2013), a ligação covalente produz um biocatalisador estável, contudo pode ocorrer perda significativa na atividade da enzima imobilizada. Caso a enzima seja termolábil, de baixo custo, e o produto final apresentar um valor razoável, pode-se aceitar perdas de atividades durante a imobilização da enzima. A ligação covalente é realizada em duas etapas. Primeiro o suporte é tratado com um reagente capaz de ativar seus grupos funcionais, após a retirada do excesso de ativador, é mantido o contato entre a enzima e o suporte com temperatura branda até a ligação covalente se estabelecer entre o suporte $e$ a enzima. A força da ligação é elevada, o que irá permitir uma grande rigidez a sua estrutura.O método de imobilização por ligação covalente multipontual é a ligação covalente entre os grupos reativos da enzima e os grupos reativos do suporte.

Sheldon; Van Pelt (2013) cita um tipo especial de imobilização por ligação covalente. A imobilização por ligações cruzada, onde as enzimas são fortemente ligadas entre si, com a utilização de um agente multifuncional.Dentre a imobilização enzimática por ligação cruzada, destaca-se o uso de polímeros acrílicos particulados ativados com grupos epóxidos como suportes, sendo bastante utilizados em escala industrial devido à sua disposição para comercialização e por possuírem resistência a estresses mecânicos e químicos.

A imobilização pelo método de adsorção consiste na utilização da enzima e um 
suporte sólido por ligações de baixa energia, tais como interação de van der Waals ou hidrofóbicas, ligações de hidrogênio e iônicas (HUDSON; COONEY; MAGNER, 2008; HARTMANN; KOSTROV, 2013). Esse tipo de imobilização é preferível quando o custo do suporte é elevado e deseja-se recuperá-lo ao ter-se a inativação total de determinada enzima. Contudo, deve-se observar a possível dessorção da enzima no meio reacional como resultado de variação no $\mathrm{pH}$ e forças iônicas, dificultando as etapas de downstrean do processo. Se o biocatalisador solúvel for termoestável e a intenção do processo de imobilização for apenas insolubilizar,deve-se utilizar um biocatalisador para uso repetido em processos de bateladas ou uso contínuo em reatores de leito fixo(SHELDON; VAN PELT, 2013;CARVALHO, 2014; POORAKBAR et al., 2018).

De acordo com Quilles Junior (2014); Meller; Szumski; Buszewski (2017), a encapsulação, também conhecida como aprisionamento, consiste na retenção do biocatalisador no interior de matrizes poliméricas ou microcápsulas semipermeáveis, sendo que não deve haver nenhuma interação química entre o suporte e os grupos constituintes da enzima, o que garante uma estrutura tridimensional e um sítio ativo sem alterações.

O procedimento da encapsulação consiste em confinar a enzima em um polímero insolúvel, poroso, em seguida o envolvimento do material biológico em membranas semipermeáveis. Aenzima fica livre no meio reacional, mas restrita a um espaço físico. As vantagens desse método é a estabilidade enzimática, pois interações físicas ou ligações químicas não são estabelecidas entre a enzima e o suporte. Outro ponto positivo é que no encapsulamento existem muitos locais de interação (FENG et al., 2015), ou seja, possui grande área superficial para o contato entre o substrato e a enzima no interior de um volume relativamente pequeno, aumentando a atividade catalítica, bem como a possibilidade de imobilização simultânea de diferentes enzimas em uma única etapa. Todavia, somente substratos de baixa massa molar podemser empregados com este tipo de enzima imobilizada, e esta é uma das principais desvantagens deste tipo de imobilização (FICANHA, 2015).

Já no método de enzimas reticuladas, envolve a formação de ligações covalentes entre as moléculas de proteína e para tanto é utilizado reagentes bifuncionais, e portanto, para esta técnica não se utiliza, ou evita-se o veículo. Os agentes de reticulação mais comumente usados são o Glutaraldeído e bis (imidoéster) (HARTMANN; KOSTROV, 2013).

$A$ interação de afinidade é referente ao transportador enxertado com ligante e a possível proteína e esta maneira tem se mostrado uma alternativa plausível (BUCUR; DANET; MARTY, 2005). Este processo permite uma ligação de alta resistência e em 
decorrência, pode resultar em um pequeno vazamento, mas sem afetar a estrutura original da proteína. A abordagem por interação de afinidade necessita a presença de funções químicas específicas sobre a proteína, isto torna na maioria das vezes a sua difusão para enzimas industriais, sendo uma desvantagem para esta abordagem (ZUCCA; SANJUST, 2014).

Tabela 2 - Vantagens e desvantagens dos métodos mais comuns de imobilização enzimática.

\begin{tabular}{|c|c|c|}
\hline MÉTODO DE IMOBILIZAÇÃO & VANTAGENS & DESVANTAGENS \\
\hline $\begin{array}{l}\text { Encapsulamento } \\
\text { aprisionamento }\end{array}$ & $\begin{array}{l}\text { - Nenhuma modificação química } \\
\text { da enzima } \\
\text { - A enzima deve reter a atividade } \\
\text { catalítica nas condições de } \\
\text { polimerização / transição do } \\
\text { suporte. }\end{array}$ & $\begin{array}{l}\text { - Vazamento de enzima } \\
\text { - Problemas de transferência em } \\
\text { massa }\end{array}$ \\
\hline Reticulação de enzimas & $\begin{array}{l}\text { - Não é necessário suporte } \\
\text { - Estabilização da enzima } \\
\text { Minimização de vazamento de } \\
\text { catalisador }\end{array}$ & $\begin{array}{l}\text { - Possível modificação química } \\
\text { maciça da enzima } \\
\text { - Processos experimentais } \\
\text { complicados } \\
\text { Problemas de transferência em } \\
\text { massa }\end{array}$ \\
\hline Adsorção & $\begin{array}{l}\text { - Nenhuma modificação química } \\
\text { da enzima } \\
\text { - Fácil e barato de ser realizado }\end{array}$ & $\begin{array}{l}\text { - Vazamento de enzima } \\
\text { Baixa especificidade da reação } \\
\text { ( ou seja, adsorção e troca iônica } \\
\text { podem se sobrepor) }\end{array}$ \\
\hline Afinidade & - Alta especificidade da reação & $\begin{array}{l}\text { - A presença de grupos } \\
\text { específicos na enzima é } \\
\text { obrigatória } \\
\text { Geralmente caro e complicado de } \\
\text { ser projetado }\end{array}$ \\
\hline Ligação covalente & $\begin{array}{l}\text { - Força da ligação } \\
\text { - Minimização de vazamento de } \\
\text { catalisador } \\
\text { - Estabilização da enzima }\end{array}$ & $\begin{array}{l}\text { - Possibilidade de modificações } \\
\text { estéricas da enzima } \\
\text { - É possível diminuir a atividade } \\
\text { enzimática } \\
\text { - São necessárias modificações } \\
\text { químicas do suporte } \\
\text { Acessório geralmente } \\
\text { irreversível, impedindo a } \\
\text { reutilização do suporte }\end{array}$ \\
\hline
\end{tabular}

Fonte: Zucca; Sanjust (2014)

\subsection{Tipos de suportes}

Segundo Costa et al. (2018), os suportes são classificados de acordo com sua composição em orgânicos e inorgânicos. Entre os orgânicos estão os polímeros naturais, sendo bastante utilizados, devido a vantagem de não causarem danos ao meio ambiente. Entre eles destaca-se a quitosana, seu sucesso deve-se às suas diferentes configurações 
geométricas como pó, escamas, hidrogeis, membranas, fibras e outras. Além da presença de diferentes grupos funcionais, como hidroxila e amino, que permitem a utilização de diferentes métodos de imobilização (MORAN et al., 2018; PEREIRA, 2015).

Outros suportes utilizados são os polissacarídeos (celulose, ágar, amido); proteínas (colágeno, seda, albumina); os inorgânicos minerais (areia, betonita, pedra-pome, horneblenda)e os sintéticos (vidro de porosidade controlada, cerâmica de porosidade controlada, sílica de porosidade controlada e óxido de ferro) (LIMA, 2013;CAO et al., 2016).

Os suportes naturais apresentam uma vantagem pertinente em relação aos sintéticos (DATTA et al.,2013), trata-se do baixo custo e a facilidade em se degradar, assim sendo menos prejudiciais ao meio ambiente após o uso (SANTOS, et al.,2014; ROSENTHAL., 2018). Contudo, os suportes inorgânicos são os mais apropriados para uso industrial por apresentarem elevada resistência mecânica, boa estabilidade térmica, resistência a solventes orgânicos e ao ataque por microrganismos(DUTRA, 2019; BRANCHER, 2011).

Vários suportes inorgânicos são usados nas mais diversas áreas, entre os mais utilizados na indústriaestão a sílicae os zeólitos (ALTINKAYNAK; TAVLASOGLU; OCSOY, 2016; DATTA et al., 2013). Esse últimopossui uma vantagem importante que é uma estabilidade, mesmo em altas temperaturas. Entretanto, há uma desvantagem, sem a formação de ligações covalentes, a enzima pode sofrer o processo de lixiviação no meio aquoso (QUILLES JUNIOR, 2014; LEE, PARK, 2015).

Os suportes de glioxil são descritoscomo eficientes para imobilização por ligação covalente multipontual. Entre as matrizes utilizadas está a agarose, um polímero natural extraído do ágar de algas vermelhas. Entre suas vantagens, destaca-se ocaráter hidrofílico, facilidade de manuseio, ausência de grupos com cargas e disponibilidade comercial, contudo uma limitação desse suporte é o alto custo (GUERRERO et al., 2017; SANTOS, 2014).

De acordo com Vasconcellos (2015), asnanozeólitas têm sido utilizadas como suporte para a imobilização enzimática e de outras proteínas devido as suas propriedades físico-químicas, bem como a grande área desuperfície externa, a alta dispersibilidade e a facilidade de modulação das suas características de superfície, especialmente, em relação à carga da superfície e propriedades de hidrofilicidade.

Ainda na área industrial, as estruturas orgânicas metálicas têm aparecido como alternativa como material de apoio, suporte, para a imobilização enzimática. Estas estruturas, como descrevem Mehta et al. (2016); RAJA et al. (2015) possuem propriedades 
exclusivas, tais como porosidade desejável, funcionalidade ideal, área superficial alta, podem ser modificados com vários grupos funcionais e ainda estabilidade térmica e estas estruturas tem sido bem explorado na pesquisa como matriz para a imobilização enzimática. A justificativa para o uso e várias pesquisas na área da biotecnologia, sobretudo, sobre a imobilização enzimática e suportes rentáveis é porque as suas vantagens são muitas e existe poucas desvantagens, como é mostrado na tabela 3.

Tabela 3 - Principais vantagens e desvantagens dos suportes orgânicos e inorgânicos

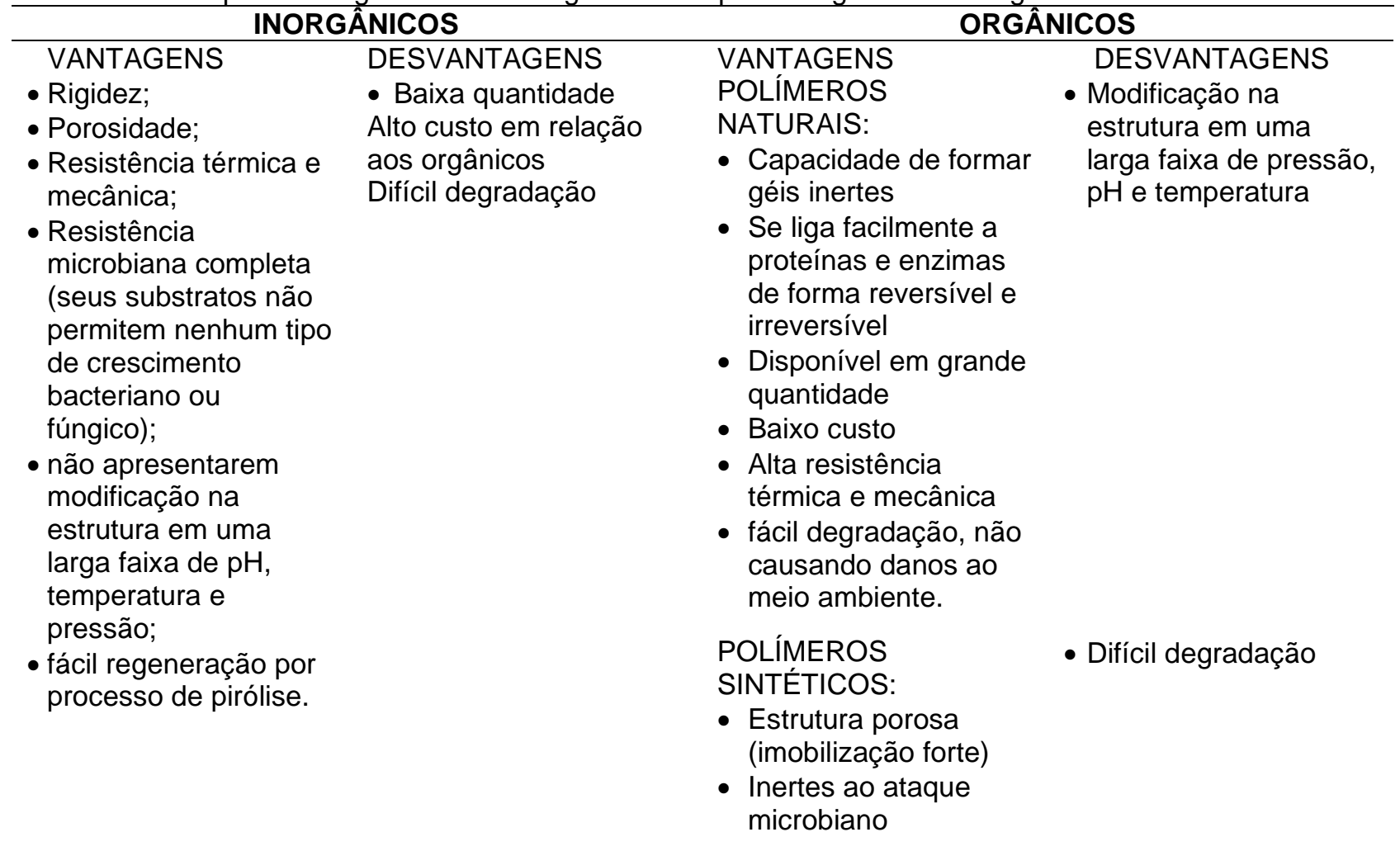

Fonte: Zucca; Sanjust (2014); Sirisha; Jain; Jain (2016).

Em uma comparação simples na Tabela 3 é possível perceber que as vantagens e desvantagens específicas dos suportes inorgânicos e suportes orgânicos (polímeros naturais e polímeros sintéticos) são poucas, já que boa parte das características se repete entre elas. Todavia, as poucas características que são únicas de cada suporte, são as que os tornam melhores e mais recomendadas por determinada indústria, a exemplo, o uso dos polímeros naturais tem crescido devido ao baixo custo, disponibilidade alta no ambiente e por formar géis inertes características não encontrada nos demais suportes (SIRISHA; JAIN; JAIN, 2016). 


\section{CONCLUSÕES}

No mundo industrializado de hoje, o grande desafio da tecnologia em enzimas tem sido o desenvolvimento de produtos e processos que não cause tantos danos ao meio ambiente. A imobilização enzimáticatem se mostrado uma ferramenta importante para a equilíbrio da enzima, permitindo a máxima reutilização e reduzindo a inativação por influência da temperatura e solventes orgânicos, sendo um atrativo para o setor industrial. Os estudos na área, ainda buscam diferentes suportes comerciais para a imobilização de enzimas. Contudo, muitos destes suportes possuem um custo elevado, o que aumenta a busca por outros de baixo custo e que possam estabilizar as enzimas de forma eficiente.

Como já citado, os suportes orgânicos possuem uma série de benefícios no seu uso como suporte, por exemplo, os suportes naturais que apresentam uma vantagem em relação aos sintéticos, por possuírem baixo custo e facilidade em se degradar após o uso, sendo menos prejudiciais ao meio ambiente, mas é percebido que no meio industrial nem sempre é utilizado o que faz bem ao meio ambiente e sim o que irá gerar mais lucro e por isso, os suportes inorgânicos por apresentarem elevada resistência mecânica, boa estabilidade térmica, resistência aos solventes orgânicos e ao ataque por microrganismos no processo e ainda porosidade e rigidez, são comumente mais vantajosos no campo industrial.

\section{REFERÊNCIAS}

ALTINKAYNAK, C; TAVLASOGLU, S; OCSOY, I. A new generation approach in enzyme immobilization: Organic-inorganic hybrid nanoflowers with enhanced catalytic activity and stability. Enzymeand microbial technology, v. 93, p. 105-112, 2016.

BRANCHER, C. M. imobilização da inulinase de kluyveromycesmarxianus NRRL Y-7571 em carvão ativado e alginato de sódio. 2011. 82 f. Dissertação (Mestrado) - Universidade Federal do Rio Grande do Sul, Faculdade de Farmácia, Programa de Pós-Graduação em Assistência Farmacêutica, Porto Alegre, -RS, 2011.

CABRERA, M. P. Imobilização de enzimas em suportes magnéticos. 2013. 183 f. Tese (Doutorado em Ciências Biológicas) - Universidade Federal de Pernambuco, Recife, 2013.

CAO, S; XU, P; MA, Y; YAO, X; YAO, Y; ZONG, M; LI, X; LOU, W. Recent advances in immobilized enzymes on nanocarriers. Chinese Journal of Catalysis, v. 37, n. 11, p. 1814-1823, 2016.

CARVALHO, N. B; LIMA, Á. S; SOARES, C. MF. Uso de sílicas modificadas para imobilização de lipases. Química Nova, v. 38, n. 3, p. 399-409, 2015. 
COSTA, M. B; LIMA, Á. S; SOARES, C. M. F; LIMA, I. S. Tecido de sílica como uma nova matriz para imobilização de lípases e aplicação em biodiesel. Semana de Pesquisa da Universidade Tiradentes-SEMPESq, n. 18, 2018.

DATTA, S; CHRISTENA, L. R; RAJARAM, Y. R. S. Enzyme immobilization: an overview on techniques and support materials. 3 Biotech, v. 3, n. 1, p. 1-9, 2013.

DONALD, V; JUDITH, G. V; CHARLOTTE, W. P. Fundamentos de Bioquímica: a vida em nível molecular. Tradução: Jaqueline Josi Samá Rodrigues et al. 4. ed. Porto alegre: Artmed, 2014.

DUTRA, C. P. Avaliação do efeito de suportes mistos de sílicas fluoradas sobre a produtividade de catalisador metaloceno suportado. 2019. 53 f. Dissertação (Mestrado em Ciência dos Materiais) - Universidade Federal do Rio Grande do Sul, Porto Alegre, 2019.

FENG, D; LIU, T. F; SU, J; BOSCH, M; WEI, Z; WAN, W; LIAN, X. Stable metal-organic frameworks containing single-molecule traps for enzyme encapsulation. Nature communications, v. 6, n. 1 , p. $1-8,2015$.

FERNÁNDEZ-FERNÁNDEZ, M; SANROMÁN, M. Á; MOLDES, D. Recent developments and applications of immobilized laccase. Biotechnology advances, v. 31, n. 8, p. 1808-1825, 2013.

FICANHA, A. M. M.; NYARI, N. L; LEVANDOSKI, K; MIGNONI, M. L; DALLAGO, R. M. Estudo da imobilização de lipase em sílica obtida pela técnica sol-gel, Química Nova, v. 38, p. 364-369, 2015.

FLORES, E. E. E. Genipina como agente ativador de esferas de quitosana como suporte para a imobilização enzimática. 2018. 46 f. Dissertação (Mestrado) - Programa de Pós-Graduação em Ciência e Tecnologia de Alimentos, Universidade Federal do Rio Grande do SulPorto Alegre, 2018.

GENNARI, A; MOBAYED, F. H; VOLPATO, G; SOUZA, C. F. Volken de. Chelation by collagen in the immobilization of Aspergillus oryzae $\beta$-galactosidase: A potential biocatalyst to hydrolyze lactose by batch processes. International journal of biological macromolecules, v. 109, p. 303-310, 2018.

GUERRERO, C; VERA, C; SEMA, N; ILLANES, A. Immobilization of Aspergillus oryzae $\beta$ galactosidase in an agarose matrix functionalized by four different methods and application to the synthesis of lactulose. Bioresource technology, v. 232, p. 53-63, 2017.

HARTMANN, M; KOSTROV, X. Immobilization of enzymes onporous silicas -benefits and challenges. Chemical Society Reviews, v. 42, n. 15, p. 6277-6289, 2013.

HOMAEI, A. A.; SARIRI, R.; VIANELLO, F.; STEVANATO, R. Enzyme immobilization: an update. Journal of Chemical Biology, v. 6, p. 185-205, 2013.

HUDSON, S; COONEY, J; MAGNER, E. Proteins in mesoporoussilicates. Angew and techemie international edition, v. 47, n. 45, p. 8582-8594, 2008.

KIRAN, S; SINGH, A; PRABHA, C; KUMARI, S; KUMARI, S. Isolation and characterization of thermostable amylase producing bacteria from hot springs of Bihar, India. Intl J Pharma Med Biol Sci, v. 7, n. 2, p. 28-34, 2018.

LEE, S-Y; PARK, S-J. A review on solid adsorbents for carbon dioxide capture. Journal of Industrial and Engineering Chemistry, v. 23, p. 1-11, 2015. 
LI, P; MODICA, J. A; HOWARTH, A. J; VARGAS, E; MOGHADAM, P. Z; SNURR, R. Q; FARHA, O. $\mathrm{K}$. Toward design rules for enzyme immobilization in hierarchical mesoporous metal-organic frameworks. Chem, v. 1, n. 1, p. 154-169, 2016.

LI, Y; YANG, D; LIU, C; YANG, P; MU, P; WEN, J; CHEN, S; LI, Y. Preparation and characterization of novel nonstoichiometric magnesium aluminate spinels. Ceramics International, [s. I.], v. 44, n. 13, p. 15104-15109, 2018.

LIMA, L. N. Síntese enzimática de ésteres catalisada por lipases imobilizadas em diferentes suportes. 2013. 154 f. Dissertação (Mestrado em Engenharia Química) - Universidade Federal de São Carlos centro de ciências exatas e de tecnologia, São Carlos-SP, 2013.

LUCKARIFT, H. R; SPAIN, J. C; NAIK, R. R; STONE, M. O. Enzyme immobilization in a biomimetic silica support. Naturebiotechnology, v. 22, n. 2, p. 211-213, 2004.

MEHTA, J; BHARDWAJ, N; BHARDWAJ, S. K; KIM, K. H; DEEP, A. Recent advances in enzyme immobilization techniques: Metal-organic frameworks as novel substrates. CoordinationChemistry Reviews, v. 322, p. 30-40, 2016.

MEI, S; HAN, P; WU, H; SHI, J;TANG, L; JIANG, Z; MELLER, K; SZUMSKI, M; BUSZEWSKI, B. One-pot fabrication of chitin-shellac composite microspheres for efficient enzyme immobilization. Journal of biotechnology, v. 266, p. 1-8, 2018.

MELLER, K; SZUMSKI, M; BUSZEWSKI, B. Microfluidic reactors with immobilized enzymescharacterization, dividing, perspectives. Sensors and Actuators B: Chemical, v. 244, p. 84-106, 2017.

MINTEER, S.D. Enzymestabilizationandimmobilization. In Methods and Protocols; Series: Methods in Molecular Biology; A productof Humana Press: New York, NY, USA, 2011.

MORAN, H. B. T; TURLEY, J. L; ANDERSSON, M; LAVELLE, C. L. Immunomodulatory properties of chitosan polymers. Biomaterials, [s. I.], v. 184, n. May, p. 1-9, 2018.

MÖRSCHBÄCHER, A. P; VOLPATO, G; SOUZA, C. F. V. Kluyveromyces lactis $\beta$-galactosidase immobilization in calcium alginate spheres and gelatin for hydrolysis of cheese whey lactose. Ciência Rural, v. 46, n. 5, p. 921-926, 2016.

NADAR, S. S; RATHOD, V. K. Magnetic-metal organic framework (magnetic-MOF): a novel platform for enzyme immobilization and nanozyme applications. International journal of biological macromolecules, v. 120, p. 2293-2302, 2018.

OLIVEIRA, M. V. S; RÓS, P. C. M; MATTEDI, S; CASTRO, H. F; SOARES, C. M. F.; LIMA, Á. S. Transesterification of babassu oil catalyzed by Burkholderiacepacia encapsulated in sol-gel matrix employing protic ionic liquid as an additive. Acta Scientiarum. Technology, v. 36, n. 3, p. 445-451, 2014.

PEREIRA, R. M. Obtenção, caracterização e utilização de hidrogel de quitosana e glicerol fosfato para imobilização de lipase de Rhizopus oryzae. 2015. 69 f. Dissertação (Mestrado em Ciência e Engenharia de Materiais) - Universidade Federal de Alfenas, Poços de Caldas, MG, 2016.

POORAKBAR, E; SHAFIEE, A; SABOURY; A. A; RAD, B. L; KHOSHNEVISAN, K; MA'MANI, L; DERAKHSHANKHAH, H; GANJALI, M. R; HOSSEINI, M. Synthesis of magnetic gold mesoporous silica nanoparticles core shell for cellulase enzyme immobilization: Improvement of enzymatic activity and thermal stability. Process biochemistry, v. 71, p. 92-100, 2018. 
QUILLES JUNIOR, J. C. Imobilização de lipases por adsorção e ligação covalente em derivados de agarose e quitosana e sua aplicação em biocatálise. 2014. 104 f. Dissertação (mestrado) - Universidade Estadual Paulista Julio de Mesquita Filho, Instituto de Biociências, Letras e Ciências Exatas, 2014

RAJA, D. S; LIU, W. L; HUANG, H. Y; LIN, C. H.. Immobilization of protein on nanoporous metalorganic framework materials. Commentson Inorganic Chemistry, v. 35, n. 6, p. 331-349, 2015.

RODRIGUES, R. C; ORTIZ, C; BERENGUER-MURCIA, Á; TORRES, R; FERNÁNDEZ-LAFUENTE, R. Modifying enzyme activity and selectivity by immobilization. Chemical Society Reviews, v. 42, n. 15, p. 6290-6307, 2013.

ROSENTHAL, A; RAUCH, S; EICHHORN, K-J; STAMM, M; UHLMANN, P. Colloids and Surfaces B: Biointerfaces Enzyme immobilization on protein-resistant PNIPAAm brushes : impact of biotin linker length on enzyme amount and catalytic activity. Colloidsand Surfaces B: Biointerfaces, v. 171 , p. 351-357, 2018.

SANTOS, A. F. Produção e imobilização de celulases em matriz de agarose com diferentes ativações químicas. 2014. 112 f. Tese (doutorado) - Universidade Estadual Paulista Júlio de Mesquita Filho, Instituto de Química de Araraquara, 2014

SANTOS, B. L; TAKAHASHI, G. S; FLEURI, L. F; PEDROSA, V. D. A.. Diferentes técnicas de imobilização enzimática para obtenção de catalisadores. Trends in Bioscience \& Biotechnology, v. 1, n. 1, p. 16-21, 2014.

SASSOLAS, A; BLUM, L. J; LECA-BOUVIER, B. D. Immobilization strategies to develop enzymatic biosensors. Biotechnology advances, v. 30, n. 3, p. 489-511, 2012.

SHELDON, R. A. Enzyme immobilization: the quest for optimum performance. Advanced Synthesis \& Catalysis, v. 349, n. 8-9, p. 1289-1307, 2007.

SHELDON, R. A; VAN PELT, S. Enzyme immobilisation in biocatalysis: why, what and how. Chemical Society Reviews, v. 42, n. 15, p. 6223-6235, 2013.

SIRISHA, V. L.; JAIN, A; JAIN, A. Enzyme immobilization: an overview on methods, support material, and applications of immobilized enzymes. In: Advances in food and nutrition research. Academic Press, 2016. p. 179-211.

TRAN, D. N; BALKUS JR, K. J. Perspective of recent progress in immobilization of enzymes. Acs Catalysis, v. 1, n. 8, p. 956-968, 2011.

VASCONCELLOS, A. Nanozeólitas como suportes sólidos para imobilização enzimática: Síntese, caracterização de complexos nanozeólitas/enzimas e sua aplicação como catalisadores heterogêneos para produção de biodiesel via rota etílica. 2015. $203 \mathrm{f}$. Tese (doutorado) - Universidade Estadual Paulista Julio de Mesquita Filho, Instituto de Biociências, Letras e Ciências Exatas, 2015.

WANG, Y; CARUSO, F. Mesoporous silica spheres as supports for enzyme immobilization and encapsulation. Chemistry of Materials, v. 17, n. 5, p. 953-961, 2005.

WEETALL, H. H. Covalent coupling methods for inorganic support materials. In: Methods in enzymology. Academic Press, 1976. p. 134-148. 
XIANG, X; SUO, H; XU, C; HU, Y. Covalent immobilization of lipase onto chitosan-mesoporous silica hybrid nanomaterials by carboxyl functionalized ionic liquids as the coupling agent. Colloids and Surfaces B: Biointerfaces, v. 165, p. 262-269, 2018.

ZHANG, L; JIAYIN, Y. D; SONG, J; QI, H. Biocompatible magnetic nanoparticles grafted by poly (carboxybetaine acrylamide) for enzyme immobilization. International journal of biological macromolecules, v. 118, p. 1004-1012, 2018.

ZHOU, Z; HARTMANN, M. Recent progress in biocatalysis with enzymes immobilized on mesoporous hosts. Topics in Catalysis, v. 55, n. 16-18, p. 1081-1100, 2012.

ZUCCA, P; SANJUST, E. Inorganic materials as supports for covalent enzyme immobilization: methods and mechanisms. Molecules, v. 19, n. 9, p. 14139-14194, 2014. 